\title{
SCIDic
}

\author{
International Journal of Dentistry and Oral Science (IJDOS) \\ ISSN: 2377-8075
}

\section{Effects Of Dentifrices On Discolouration Of Cad Cam Manufactured Temporary Restorative Materials}

Research Article

Amirtha Varshini ${ }^{1}$, Karthickraj S.M ${ }^{2 *}$

${ }^{1}$ Saveetha Dental College and Hospitals, Saveetha Institute of Medical and Technical Sciences (SIMATS), Saveetha University, Chennai- 77, India. ${ }^{2}$ Senior Lecturer, Department of Periodontics, Saveetha Dental College and Hospitals, Saveetha Institute of Medical and Technical Sciences [SIMATS], Saveetha University, Chennai- 77, India.

Abstract

Aim: To assess the effects of dentifrices on discolouration of CAD/CAM manufactured temporary restorative materials. Introduction: Color match is one of the most important characteristics of aesthetic restorative materials. Maintenance of color throughout the functional lifetime of restorations is important for the durability of treatment. This characteristic is not constant among dental materials. Restorative materials must maintain long-term color stability in order to avoid replacement of restorations. Color differences $(\Delta \mathrm{E})$ more than 3.3 units reflect clinically significant visual discoloration. The degree of discoloration of resins can be influenced by a number of factors such as incomplete polymerization, water sorption, chemical reactivity, diet, oral hygiene or surface roughness of the restoration. Discoloration can be due to extrinsic or intrinsic cause. The null hypothesis was that colour stability of tested materials were not affected by the dentifrices or toothbrushing simulation. Materials and Methods: In this study, CAD/CAM manufactured PMMA blocks were used. The blocks were mounted with a die and the preoperative values for colour stability were recorded using Digital spectrophotometer (VITA Easyshade Advance 4.0- VITA Zahnfabrik). The values included "l", "c", "h", "a", "b" values. Then the PMMA blocks were subjected to toothbrush simulator (Toothbrush simulator ZM3.8- SD Mechatronik). The simulator was run for 1 month cycle (i.e. 833 cycles) and 3 month cycle (i.e. 2500 cycles). Then the values were recorded again.

Results and Discussion: Results show that there is no significant differences between colour stability of PMMA blocks before and after brushing with different dentifrices for 1 month and 3 month cycles. The graph shows the delta $E$ values for the samples treated with different dentifrices for the 1st month, 3rd month and between 1st and 3rd month. P values for 1 month, 3 month and between 1 and 3 months cycles were found to be $0.992,0.25$ and 0.895 . Hence the values are not statistically significant.

Conclusion: This study concludes that different dentifrices have no effect on discolouration of CAD/CAM manufactured temporary restorative materials.

Keywords: Dentifrices; Discolouration; Pmma Blocks; Innovative Technology; Toothbrush Simulator; Spectrophotometer.

\section{Introduction}

Color, shape and surface texture are very important in aesthetics characterising and personalising a smile [1]. Even though aesthetic treatments have been one of the most required dental treatments, coming just after pain related treatments, in depth property of aesthetic restaurateur material is their long-term colour stability and an acceptable colour match is the primary reason for the replacement of composite resin restoration [2]. As possessing good esthetic properties, resin composite materials are widely used in clinical practice. Any aesthetic restorative material should duplicate the appearance of a natural tooth in colour and the success of an aesthetic restoration depends first on the colour match and then on the Colour stability of the material [3].

Three types of discolouration are generally described : external discolouration due to their accumulation of plaque and surface stains(extrinsic stain), Surface or subsurface colour alteration implying superficial degradation or slight penetration and reaction of staining agents within the superficial layer of composite resins

\footnotetext{
*Corresponding Author:

Dr. Karthickraj S.M,

Senior Lecturer, Department of Periodontics, Saveetha Dental College and Hospitals, Saveetha Institute of Medical and Technical Sciences [SIMATS], Saveetha University, Chennai- 77, Tamil Nadu, India.

E-mail: karthickrajsm.sdc@saveetha.com
}

Received: September 13, 2021

Accepted: September 22, 2021

Published: September 23, 2021

Citation: Amirtha Varshini, Karthickraj S.M. Effects Of Dentifrices On Discolouration Of Cad Cam Manufactured Temporary Restorative Materials. Int J Dentistry Oral Sci. 2021;8(9):4553-4556. doi: http://dx.doi.org/10.19070/2377-8075-21000927

Copyright: Dr. Karthickraj S.M ${ }^{\odot} 2021$. This is an open-access article distributed under the terms of the Creative Commons Attribution License, which permits unrestricted use, distribution and reproduction in any medium, provided the original author and source are credited. 
and body or intrinsic discolouration due to physio chemical reactions in the deeper portion of the restoration [4]. Discolouration of composite resin materials can be caused By Intrinsyc and/ or extrinsic factors [5]. The new resin based CAD/CAM blocks combining the strength and colour stability of ceramics with the improved flexibility and low abrasiveness of composites have been made available for the dental practice [6]. However it has been stated that the optical and mechanical properties of these materials should be acceptable for long term use [7].

The esthetic appearance of the teeth restored with composite resins affect the characteristic features such as the surface roughness, brightness, colour stability of the restorative material [8]. Discolouration occurring over time will probably limit the longevity and perceived quality of restorations. Colour changes of dental restorations could vary depending on oral hygiene, diet and smoking habits of patients. When exposed to the oral environment, discolouration may occur due to external and internal factors [9]. Among external factors, colour change occurs by adsorption of colorants because of contamination from exogenous sources. The aim of this study was to investigate the effects of dentifrices on discolouration of CAD/CAM manufactured temporary restorative materials.

\section{Materials and Methods}

In this study, CAD/CAM manufactured PMMAblocks were used. 8 samples of PMMA blocks were collected from the CAD/CAM department valueof Saveetha dental college and hospitals. The blocks were mounted and preoperative values for colour stability were recorded using spectrophotometer (VITA Easyshade Advance 4.0- VITA Zahnfabrik). . The values included L,c,h,a,b values. The PMMA blocks were then subjected to toothbrush simulator (Toothbrush simulator ZM3.8- SD Mechatronik). Four different pastes that were commercially available was applied onto the blocks. Dabur red toothpaste was used for the first two samples , Meswak toothpaste was used for the next two samples, sensodyne toothpaste was used for the next two samples and Colgate toothpaste was used for the last two samples and the simulator was run for 1 month cycle (i.e 833 cycles) in a linear motion (x and y axis). The values $\mathrm{L}, \mathrm{c}, \mathrm{h}, \mathrm{a}, \mathrm{b}$ for 1 month cycle were recorded and then again subjected to the simulator continuously after 833 cycles till 2500 cycles ( 3 month cycle). Then the 3 month cycle values were recorded.

\section{Results and Discussion}

8 samples of PMMA blocks were collected and the brushing was done for 4 randomly chose toothpastes using a toothbrush simulator. The values for each sample (pre op and post op) were recorded.In this study, a clinical spectrophotometer (Vita Easyshade Advance) and the $\mathrm{L}^{*}, \mathrm{a}^{*}$, and $\mathrm{b}^{*}$ CIE coordinate system were utilized, as they were reported to offer more objective values with a higher level of accuracy and repeatability. In the system of $\mathrm{CIELAB}$, color difference $\Delta \mathrm{E}$ is the value used to evaluate color changes and it is calculated by a special formula using the differences in $\mathrm{L}^{*}, \mathrm{a}^{*}$, and $\mathrm{b}^{*}$ values.

\section{$\Delta \mathrm{E}=[\Delta \mathrm{a} 2+\Delta \mathrm{b} 2-\Delta \mathrm{L} 2]^{1 / 2}$}

Where, L - lightness and darkness, a - greenish or reddish and b bluish or yellowish.

There is no observable difference for 1 month cycle in all the tooth pastes. On analysing the 3 month cycle, Colgate tooth paste showed a relatively higher discolouration among all tooth pastes and Sensodyne tooth paste showed a higher discolouration next to Colgate toothpaste. On analysing the colour change between 1 month and 3 month cycle, Sensodyne tooth paste showed a higher rate of colour change when compared to other toothpastes. Although there are some differences observed from the graph, Results show that there is no significant differences between colour stability of PMMA blocks before and after brushing with different dentifrices for 1 month and 3 month cycles. The graph (fig. 1) shows the delta $E$ values for the samples treated with different dentifrices for the 1st month, 3rd month and between 1st and 3rd month. P values for 1 month, 3 month and between 1 and 3 months cycles were found to be $0.992,0.25$ and 0.895 ( $p<0.05$ is considered significant). Hence the values are not statistically significant. Our team has extensive knowledge and research experience that has translate into high quality publications [10-29].

Color stability is the ability of any dental material to retain its original color. The color stability of resin composite is related to the resin matrix, dimensions of filler particles, depth of polymerization, coloring agents, and certain extrinsic and intrinsic factors. The most prominent disadvantage of resin-based CAD/ CAM blocks used for esthetic restoration of teeth is unpredictable color change and staining occurring over time. Discoloration or loss of translucency in restorative materials can lead to patient dissatisfaction [30].

As a result of abrasion by brushing, as well as by the corrosive process (erosion), restorative materials can become rough and wear out. The presence of irregularities can influence the appear-

\begin{tabular}{|c|c|c|c|c|c|c|}
\hline \multicolumn{9}{|c|}{ ANOVA } & Sig. \\
\hline \multicolumn{2}{|c|}{$\begin{array}{c}\text { Mean Delta E Values } \\
\text { for First month cycle }\end{array}$} & Sum of Squares & df & Mean Square & F & Sig. \\
\cline { 2 - 8 } & Within Groups & 4.38 & 8 & 0.018 & 0.032 & 0.992 \\
\hline & Total & 4.433 & 11 & & & \\
\hline \multirow{3}{*}{$\begin{array}{c}\text { Mean Delta E Values } \\
\text { for Third month cycle }\end{array}$} & Between Groups & 2.843 & 3 & 0.948 & 1.670 & 0.250 \\
\cline { 2 - 8 } & Within Groups & 4.539 & 8 & 0.567 & & \\
\hline $\begin{array}{c}\text { Mean Delta E Values } \\
\text { between First and } \\
\text { Third month cycle }\end{array}$ & Total & 7.382 & 11 & & & \\
\cline { 2 - 8 } & Wetween Groups & 0.294 & 3 & 0.098 & 0.198 & 0.895 \\
\cline { 2 - 8 } & Tithin Groups & 3.96 & 8 & 0.495 & & \\
\hline
\end{tabular}


Figure 1. Graph representing the mean delta $\mathrm{E}$ values for different dentifrices with tooth simulation at 1st month, at 3rd month and between 1st and 3rd month. P values for 1 month, 3 month and between 1 and 3 months cycles were found to be $0.992,0.25$ and 0.895 which are statistically insignificant implying that there are no significant differences in the mean delta $E$ values between the different dentrifices.

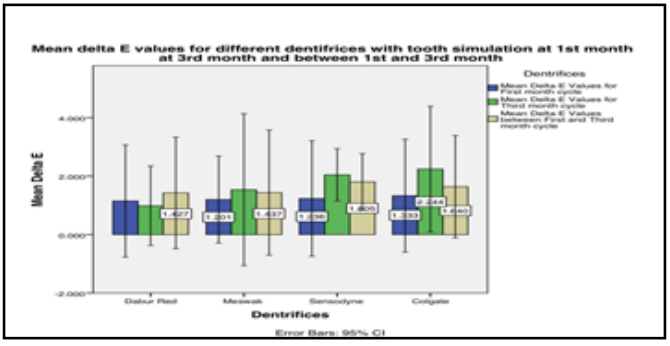

ance, lead to surface discoloration, bacterial biofilm retention and gingival irritation, increasing the risk of caries and periodontal inflammation. The important factors affecting color stability are the surface roughness, surface integrity, finishing, and polishing techniques.

In a study by Cesar and Regina [31] there was no difference in color stability between brushed and not brushed specimens, regardless of toothpaste used, showing that despite the greater roughness of the brushed specimens, did not result in color change which is in accordance with our study.

Also, the present study result is contradicted in a previous study (2) that use of whitening tooth paste will cause colour change and surface roughness of restorative material making it prone to deformation and also affects the clinical success of restoration.

\section{Conclusion}

Toothbrushing also brings negative effects over a period of time whether done or not done appropriately to maintain oral hygiene on the surface of composite restorations. Within the limitations of this study, the $\Delta \mathrm{E}$ values after tooth simulation for a period of time did not significantly change. Hence, this study concludes that different dentifrices have no effect on discolouration of CAD/ CAM manufactured temporary restorative materials.

\section{Acknowledgement}

Saveetha dental college and Hospitals, Saveetha institute of Medical and Technical Science, Saveetha University.

\section{Source of Funding}

The present study was supported by the following agencies

- Saveetha Dental college and Hospitals

- Saveetha Institute of Medical and Technical Sciences

- Saveetha University

- SJ Enterprises Pvt Ltd

\section{References}

[1]. Roopa KB, Basappa N, Prabhakar AR, Raju OS, Lamba G. Effect of Whitening Dentifrice on Micro Hardness, Colour Stability and Surface Roughness of Aesthetic Restorative Materials. J Clin Diagn Res. 2016 Mar;10(3):ZC06-11.Pubmed PMID: 27134991

[2]. Villalta P, Lu H, Okte Z, Garcia-Godoy F, Powers JM. Effects of staining and bleaching on color change of dental composite resins. J Prosthet Dent.
2006 Feb 1;95(2):137-42.

[3]. Sarac D, Sarac YS, Kulunk S, Ural C, Kulunk T. The effect of polishing techniques on the surface roughness and color change of composite resins. J Prosthet Dent. 2006 Jul 1;96(1):33-40.

[4]. Poggio C, Vialba L, Berardengo A, Federico R, Colombo M, Beltrami R, et al. Color stability of new esthetic restorative materials: A spectrophotometric analysis. J. Funct. Biomater. 2017 Sep;8(3):26.

[5]. Bagheri R, Burrow MF, Tyas M. Influence of food-simulating solutions and surface finish on susceptibility to staining of aesthetic restorative materials. J Dent. 2005 May;33(5):389-98.Pubmed PMID: 15833394

[6]. Coldea A, Swain MV, Thiel N. Mechanical properties of polymer-infiltratedceramic-network materials. Dent Mater . 2013 Apr 1;29(4):419-26.

[7]. Liebermann A, Spintzyk S, Reymus M, Schweizer E, Stawarczyk B. Nine prophylactic polishing pastes: impact on discoloration, gloss, and surface properties of a CAD/CAM resin composite. Clin Oral Investig. 2019 Jan;23(1):327-335.Pubmed PMID: 29658069.

[8]. Lainović T, Blažić L, Kukuruzović D, Vilotić M, Ivanišević A, Kakaš D. Effect of diamond paste finishing on surface topography and roughness of dental nanohybrid composites-AFM analysis. Procedia Eng. 2014 Jan 1;69:945-51.

[9]. Alharbi A, Ardu S, Bortolotto T, Krejci I. Stain susceptibility of composite and ceramic CAD/CAM blocks versus direct resin composites with different resinous matrices. Odontology. 2017 Apr;105(2):162-169.Pubmed PMID: 27456684.

[10]. Ramesh A, Varghese S, Jayakumar ND, Malaiappan S. Comparative estimation of sulfiredoxin levels between chronic periodontitis and healthy patients - A case-control study. J Periodontol. 2018 Oct;89(10):1241-1248.Pubmed PMID: 30044495

[11]. Paramasivam A, Priyadharsini JV, Raghunandhakumar S, Elumalai P. A novel COVID-19 and its effects on cardiovascular disease. Hypertens Res. $2020 \mathrm{Jul} ; 43(7): 729-30$.

[12]. S G, T G, K V, Faleh A A, Sukumaran A, P N S. Development of 3D scaffolds using nanochitosan/silk-fibroin/hyaluronic acid biomaterials for tissue engineering applications. Int J Biol Macromol. 2018 Dec;120(Pt A):876885.Pubmed PMID: 30171951.

[13]. Del Fabbro M, Karanxha L, Panda S, Bucchi C, Doraiswamy JN, Sankari $\mathrm{M}$, et al. Autologous platelet concentrates for treating periodontal infrabony defects. Cochrane Database Syst Rev. 2018;11: CD011423.

[14]. Paramasivam A, Vijayashree Priyadharsini J. MitomiRs: new emerging microRNAs in mitochondrial dysfunction and cardiovascular disease. Hypertens Res. 2020 Aug;43(8):851-853.Pubmed PMID: 32152483

[15]. Jayaseelan VP, Arumugam P. Dissecting the theranostic potential of exosomes in autoimmune disorders. Cell Mol Immunol. 2019 Dec;16(12):935-936. Pubmed PMID: 31619771.

[16]. Vellappally S, Al Kheraif AA, Divakar DD, Basavarajappa S, Anil S, Fouad $\mathrm{H}$. Tooth implant prosthesis using ultra low power and low cost crystalline carbon bio-tooth sensor with hybridized data acquisition algorithm. Comput Commun. 2019 Dec 15;148:176-84.

[17]. Vellappally S, Al Kheraif AA, Anil S, Assery MK, Kumar KA, Divakar DD. Analyzing Relationship between Patient and Doctor in Public Dental Health using Particle Memetic Multivariable Logistic Regression Analysis Approach (MLRA2). J Med Syst. 2018 Aug 29;42(10):183.Pubmed PMID: 30155746.

[18]. Varghese SS, Ramesh A, Veeraiyan DN. Blended Module-Based Teaching in Biostatistics and Research Methodology: A Retrospective Study with Postgraduate Dental Students. J Dent Educ. 2019 Apr;83(4):445-450.Pubmed PMID: 30745352.

[19]. Venkatesan J, Singh SK, Anil S, Kim SK, Shim MS. Preparation, Characterization and Biological Applications of Biosynthesized Silver Nanoparticles with Chitosan-Fucoidan Coating. Molecules. 2018 Jun 12;23(6):1429.Pub- 
med PMID: 29895803.

[20]. Alsubait SA, Al Ajlan R, Mitwalli H, Aburaisi N, Mahmood A, Muthurangan $\mathrm{M}$, et al. Cytotoxicity of different concentrations of three root canal sealers on human mesenchymal stem cells. Biomolecules. 2018 Sep;8(3):68.

[21]. Venkatesan J, Rekha PD, Anil S, Bhatnagar I, Sudha PN, Dechsakulwatana C, et al. Hydroxyapatite from cuttlefish bone: isolation, characterizations, and applications. Biotechnol Bioprocess Eng. 2018 Aug;23(4):383-93.

[22]. Vellappally S, Al Kheraif AA, Anil S, Wahba AA. IoT medical tooth mounted sensor for monitoring teeth and food level using bacterial optimization along with adaptive deep learning neural network. Measurement. 2019 Mar $1 ; 135: 672-7$

[23]. PradeepKumar AR, Shemesh H, Nivedhitha MS, Hashir MMJ, Arockiam S, Uma Maheswari TN, et al. Diagnosis of Vertical Root Fractures by Conebeam Computed Tomography in Root-filled Teeth with Confirmation by Direct Visualization: A Systematic Review and Meta-Analysis. J Endod. 2021 Aug;47(8):1198-1214.Pubmed PMID: 33984375.

[24]. R H, Ramani P, Tilakaratne WM, Sukumaran G, Ramasubramanian A, Krishnan RP. Critical appraisal of different triggering pathways for the pathobiology of pemphigus vulgaris-A review. Oral Dis. 2021 Jun 21.Pubmed PMID: 34152662.

[25]. Ezhilarasan D, Lakshmi T, Subha M, Deepak Nallasamy V, Raghunandhakumar $S$. The ambiguous role of sirtuins in head and neck squamous cell carcinoma. Oral Dis. 2021 Feb 11.Pubmed PMID: 33570800.

[26]. Sarode SC, Gondivkar S, Sarode GS, Gadbail A, Yuwanati M. Hybrid oral potentially malignant disorder: A neglected fact in oral submucous fibrosis. Oral Oncol. 2021 Jun 16:105390.Pubmed PMID: 34147361.

[27]. Kavarthapu A, Gurumoorthy K. Linking chronic periodontitis and oral cancer: A review. Oral Oncol. 2021 Jun 16:105375

[28]. Vellappally S, Al-Kheraif AA, Anil S, Basavarajappa S, Hassanein AS. Maintaining patient oral health by using a xeno-genetic spiking neural network. J Ambient Intell Humaniz Comput. 2018 Dec 14:1-9.

[29]. Aldhuwayhi S, Mallineni SK, Sakhamuri S, Thakare AA, Mallineni S, Sajja R, et al. Covid-19 Knowledge and Perceptions Among Dental Specialists: A Cross-Sectional Online Questionnaire Survey. Risk Manag Healthc Policy. 2021 Jul 7;14:2851-2861.Pubmed PMID: 34262372.

[30]. Stawarczyk B, Sener B, Trottmann A, Roos M, Ozcan M, Hämmerle CH. Discoloration of manually fabricated resins and industrially fabricated CAD/ CAM blocks versus glass-ceramic: effect of storage media, duration, and subsequent polishing. Dent Mater J. 2012;31(3):377-83.Pubmed PMID: 22673470.

[31]. Lepri CP, Palma-Dibb RG. Surface roughness and color change of a composite: influence of beverages and brushing. Dent Mater J. 2012;31(4):689-96. Pubmed PMID: 22864226. 